Klaus Kayser ${ }^{\mathrm{a}}$

Monika Plodziszewska ${ }^{\mathrm{c}}$

Elzbieta Waitrc

Janina Slodkowska

Mithat Altiner

Hans-Joachim Gabius ${ }^{\mathrm{b}}$

a Department of Pathology, Thoraxklinik, Heidelberg and

b Institute of Physiological Chemistry, Ludwig-Maximilians University,

München, Germany;

c Department of Pathology, Institute of

Tuberculosis and Lung Diseases,

Warsaw, Poland

\section{Diffuse Pulmonary Hemosiderosis after Exposure to Pesticides}

\author{
A Case Report
}

\section{Key Words}

Diffuse pulmonary hemosiderosis

Pesticide

Cyclophosphamide

Prednisone

\begin{abstract}
This report describes the clinical, radiological, microscopical and ligandohistochemical findings in a 17-year-old woman who suffered from an acute onset of pulmonary hemosiderosis after inhalation of pesticides used for the cultivation of strawberries. She complained of headache, dyspnea, rhinitis, weakness and recurrent severe hemoptysis. Chest radiographs revealed bilateral patchy infiltrates, predominantly in the lower parts of both lungs. The consecutive severe anemia was treated by multiple blood transfusions which were repeated every 4-5 days. Open lung biopsies displayed signs of diffuse hemorrhage with hemosiderin-loaded macrophages, some hyaline membranes, focal fibroid deposits with intermingled histiocytes, mild interstitial fibrosis and focal intra-alveolar calcified bodies surrounded by foreign body giant cells. Analysis of endogenous lectins failed to demonstrate expression of binding capacities for maltose, fucose, mannose, lactose and sialic acid. Neither binding capacities for the macrophage-migration-inhibitory factor nor its presence, as analyzed by labeled sarcolectin, could be detected histochemically. The light microscopical findings are consistent with a longer-lasting diffuse pulmonary hemosiderosis; the presence of calcified bodies and foreign body giant cells (including the ligandohistochemical data) argues for a causal role of inhaled substances. The patient's clinical course improved after cyclophosphamide treatment, which restored her ability to work and released her from the need for recurrent blood transfusions.
\end{abstract}

\section{Introduction}

Diffuse pulmonary hemosiderosis is histologically defined by inflammatory alterations of the lung parenchyma, associated with increased intrapulmonary deposits of hemosiderin [1-3]. Its major clinical manifestation is diffuse pulmonary hemorrhage [4-9]. It is a rare disease which is seen in children and young adults (up to 30 years of age); adults are less frequently affected. Most of the described cases have been reported without mentioning exposure to causative or associated agents, and the disease is commonly listed in textbooks under the term of idiopathic pulmonary hemosiderosis $[10,11]$. Reactivity for antiglomerular basement membrane antibody is usually

\section{KARGER \\ Fax +4161306 1234 \\ E-Mail karger@karger.ch} www. karger.com

\section{(c) 1998 S. Karger AG, Basel \\ $0025-7931 / 98 / 0653-0214 \$ 15.00 / 0$}

This article is also accessible online at: http://BioMedNet.com/karger
Professor Dr. Dr. Klaus Kayser

Department of Pathology

Thoraxklinik, Amalienstr. 5

D-69126 Heidelberg (Germany)

Tel. +49 62213964 96, Fax +496221396238 
absent, as well as clinical signs of glomerulonephritis or related diseases $[12,13]$. A few authors reported associations of pulmonary hemosiderosis with gluten-sensitive enteropathy or hypersensitivity against cow's milk (Heifer's syndrome) [14-18]. Elevated serum IgA levels are found in about $50 \%$ of the patients [3, 6, 19]. Among exogenous substances described to be associated with diffuse pulmonary hemosiderosis, exposure to large amounts of trimellitic anhydride has been reported [20]. This substance is used in the plastic-producing industry, and elevated serum levels of this substance could be demonstrated in exposed workers [20]. The course of the disease is usually poor, especially in young children, whereas young adults have a reasonable prognosis $[3,10]$. We here report the clinical, radiological and histopathological findings of a young female patient. The characteristics of her disease are related to the features of an idiopathic pulmonary hemosiderosis and associated with the exposure to pesticides.

\section{Case Presentation and Findings}

This 17 -year-old woman was living in a farmer's family and involved in the daily work of a small family farm, including the cultivation of strawberries. Until the onset of her disease, neither severe disorders nor a genetic family burden had been reported. She was a HIV-negative nonsmoker with no history of alcohol or other drug abuse at the time when she sprayed and inhaled for about 6 hours the following substances during cultivation of strawberries in summer time (July): (1) DECIS (deltamethrin [(S) $\alpha$-cyano-3-phenoxybenzyl(1R,3R)-3-(2,2-dibromvinyl )-2,2-dimethylcyclopropanecarboxylate], synthetic peritroids, class IV of toxicity); (2) BANKOL (bensultap, tiosulfonians, class III of toxicity), and (3) KARATE (lambdacyhalothrin [ $\alpha$-cyano - 3 - phenoxybenzyl - 3-(2-chlor-3,3,3-trifluoroprop-1-enyl)-2,2-dimethylcyclopropanecarboxylate], class III of toxicity). About 4 days later, she developed dyspnea, rhinitis, weakness and moderate hemoptysis and was admitted to a regional hospital and afterwards referred to the Institute of Tuberculosis and Lung Diseases in Warsaw. Upon admission to the Institute, she was pale and tired, with dyspnea on minimal exertion. Bilateral inspiratory rales were found on both lungs. Digital clubbing was absent. Chest $\mathrm{X}$-rays revealed bilateral patchy infiltrations, predominantly in the lower parts of both lungs (fig. 1). Laboratory data included: hemoglobin concentration $8 \mathrm{~g} / \mathrm{dl}$, red blood cell count $2,390,000 / \mathrm{mm}^{3}$, including $75 \%$ reticulocytes, and leukocyte count $6,600 / \mathrm{mm}^{3}$, with normal subpopulations (eosinophiles $2 \%$ ). Coombs test was negative. Neither antinuclear antibodies nor antibodies against the cytoplasm of granulocytes were found. Urine and stool analyses were without pathological findings. The following serum levels were defined: total protein $6.1 \mathrm{~g} / \mathrm{dl}$, albumin $67.9 \%, \alpha-1$ globulin $2.8 \%, \alpha-2$ globulin $8.4 \%$, $\beta$-globulin $10.4 \%$, $\gamma$-globulin $10.5 \%$, blood creatinine $0.7 \mathrm{mg} /$ $\mathrm{dl}$, glutamic-oxaloacetic transaminase $26 \mathrm{U} / 1$, glutamic pyruvic transaminase $9 \mathrm{U} / \mathrm{l}$, alkaline phosphatase $32 \mathrm{U} / \mathrm{l}$, bilirubin $0.7 \mathrm{mg} / \mathrm{dl}$ and iron $46 \mathrm{ng} / \mathrm{dl}$. Routine blood gas analysis revealed mild function-

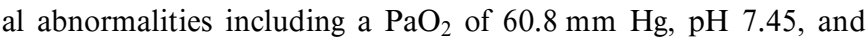

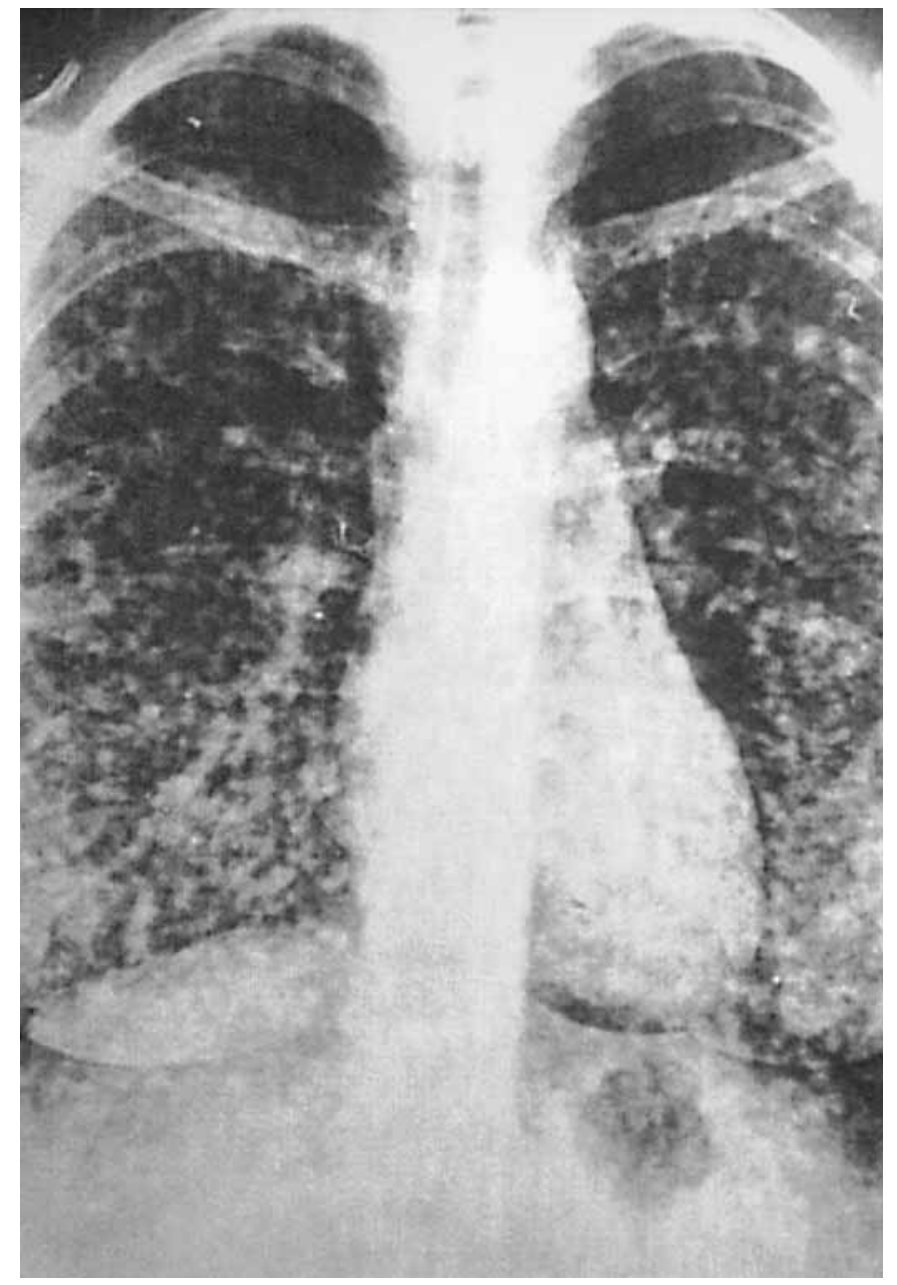

Fig. 1. Chest radiograph showing diffuse dense infiltrates of both lungs, predominantly in the lower parts.

$\mathrm{PaCO}_{2}$ of $32.6 \mathrm{~mm} \mathrm{Hg}$. At bronchoscopy, a severe mucosanguineous secretion was seen within the otherwise normal major bronchi. Analysis of the bronchoalveolar lavage fluid revealed numerous hemosiderin-loaded macrophages. After performance of a wedge biopsy (see below), the patient was treated with prednisone ( $1 \mathrm{mg} / \mathrm{kg}$, equivalent to a daily dose of $50 \mathrm{mg}$ ). During this treatment, she continued to experience hemoptysis and required blood transfusions every 4-5 days. After 14 days, azathioprine (100 mg/day) was added to the prednisone treatment; however, no improvement was noted. After 4 weeks, the treatment included cyclophosphamide $(2 \mathrm{mg} / \mathrm{kg})$ in addition to prednisone. Thereafter, a constant improvement of her health condition was seen. After discharge, she continued to be treated with cyclophosphamide $1,000 \mathrm{mg}$ intravenously once every 6 weeks and prednisone at a dosis of $15 \mathrm{mg}$ every second day. Blood transfusions were no longer needed. She was feeling well and went back to work. Physical examinations of her chest were normal, although her chest 


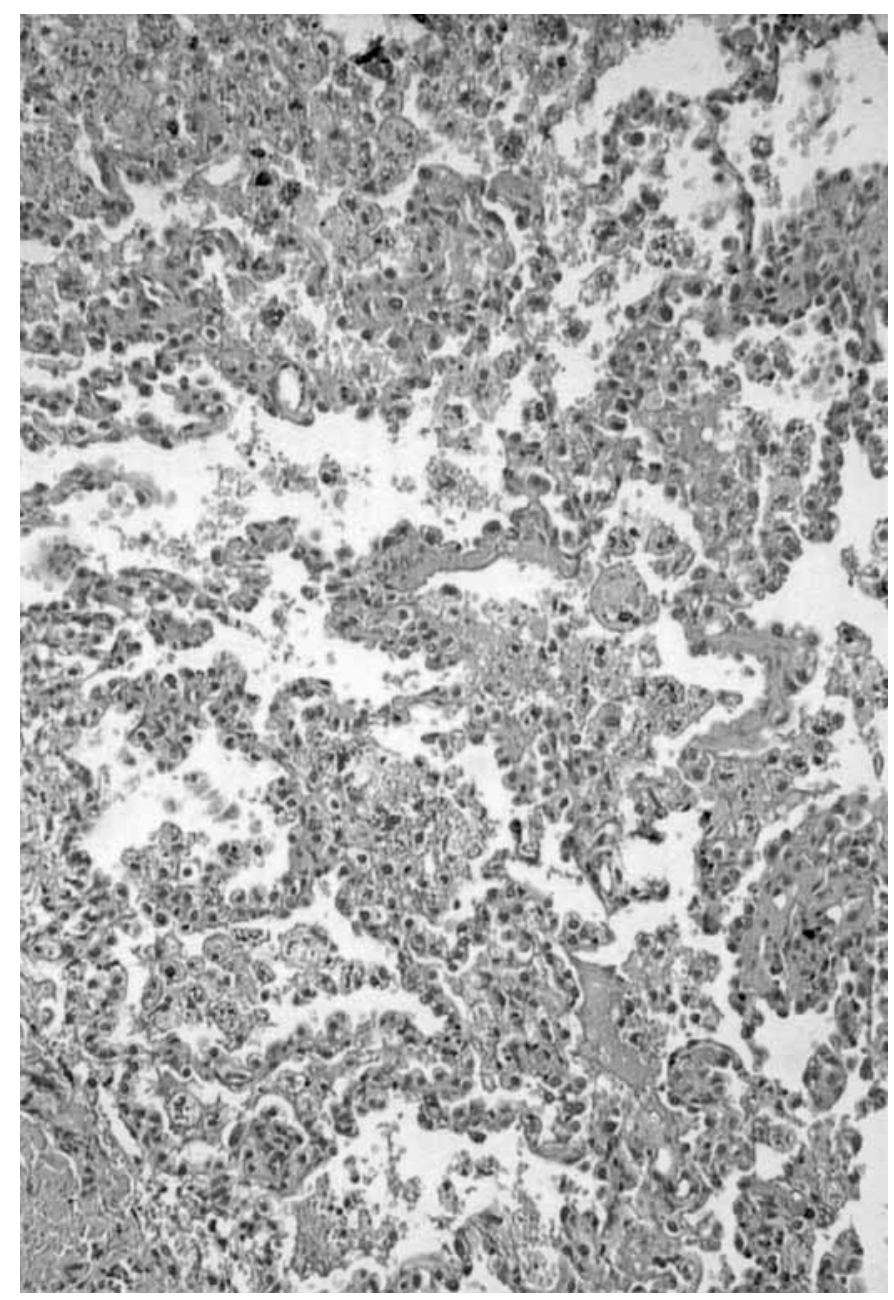

Fig. 2. Microphotograph showing the still preserved lung texture and a marked hyperplasia and dysplasia of the cells of the alveolar lining. HE. $\times 185$.

$\mathrm{X}$-rays still demonstrated diffuse infiltrations. These were less pronounced after therapy compared to the initial X-rays. Her hemoglobin level increased to $13 \mathrm{~g} / \mathrm{dl}$, the erythrocyte count to $3,900,000 /$

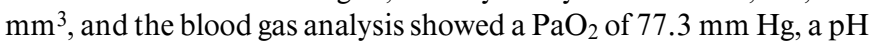
of 7.4 and $\mathrm{PaCO}_{2}$ of $35 \mathrm{~mm} \mathrm{Hg}$.

\section{Pathohistological Findings}

The lung parenchyma taken by an open lung biopsy (wedge biopsy) displayed signs of a longer-lasting intrapulmonary hemorrhage with still preserved lung texture, focal calcified bodies, including a few foreign body giant cells, and altered cells of the alveolar lining (fig. 2). The inflammatory infiltrates were weak and consisted of lymphocytes and plasma cells. Hemosiderin-loaded macrophages were the predominant feature (fig. 3). Some areas displayed small hyaline membranes and fibroid deposits with intermingled histiocytes; in addition, some fibroid plugs could be noted in the small bronchi

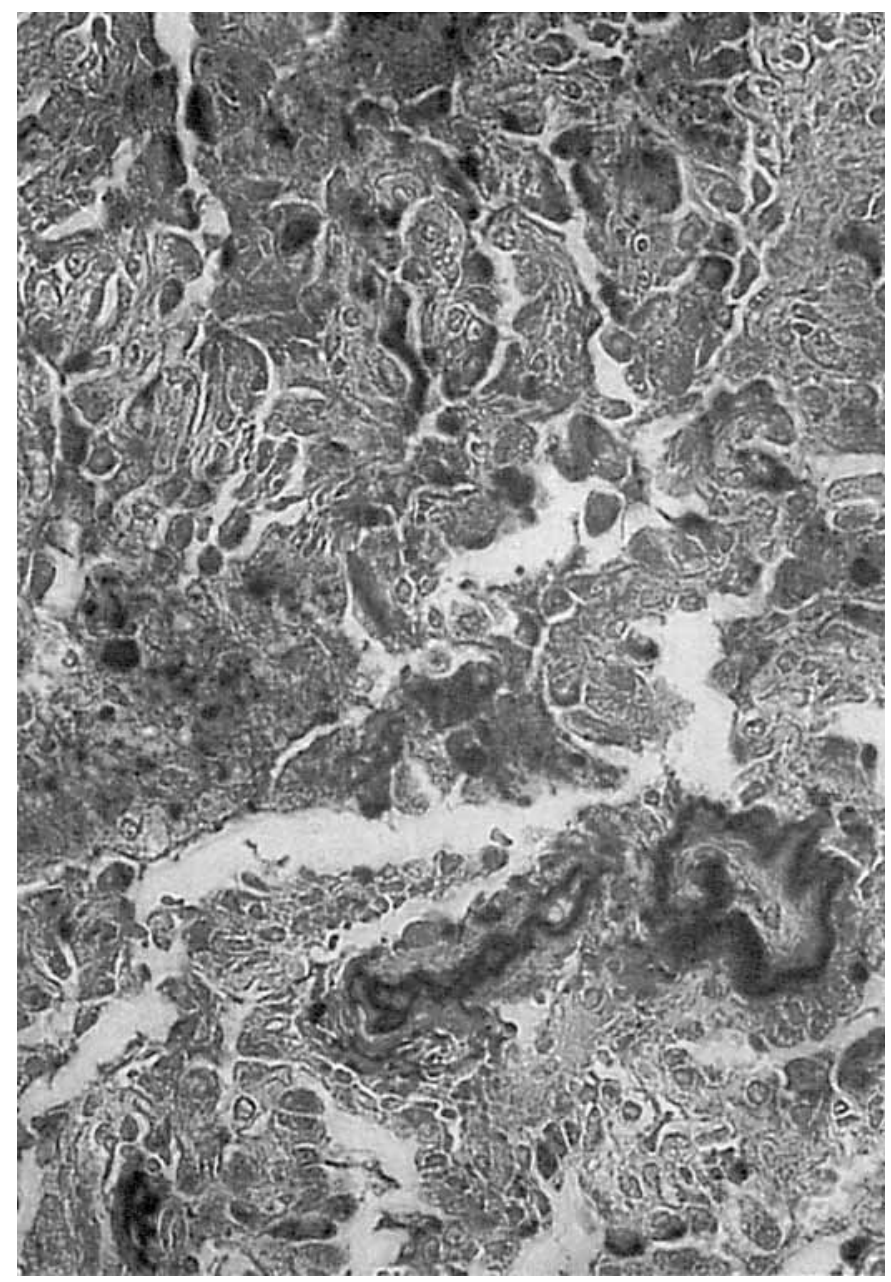

Fig. 3. Microphotograph showing hemosiderin-loaded macrophages, a marked desquamation of the cells of the alveolar lining and hemosiderin deposits in the walls of small arteries and veins. Prussian blue. $\times 185$.

( $>10$ th generation). The pneumocytes appeared hyperplastic and dysplastic, whereas the texture of the vascular system (arteries and veins) was of normal configuration. There was already a moderate focal interstitial fibrosis (fig. 4). Application of neoglycoproteins failed to detect fucose-, maltose-, mannose- and sialic-acid-specific binding capacities. No expression of $\operatorname{IgA}, \operatorname{IgG}$ or $\operatorname{IgE}$ could be detected immunohistochemically. However, a disturbance of the cellular immune system appeared to exist, as inferable by a lack of presence of macrophage-migration-inhibitory factor (MIF), probed ligandohistochemically by biotinylated sarcolectin, and of MIF-binding sites. These findings were in agreement with data reported from lung involvement in autoimmune disorders [21-23]. 


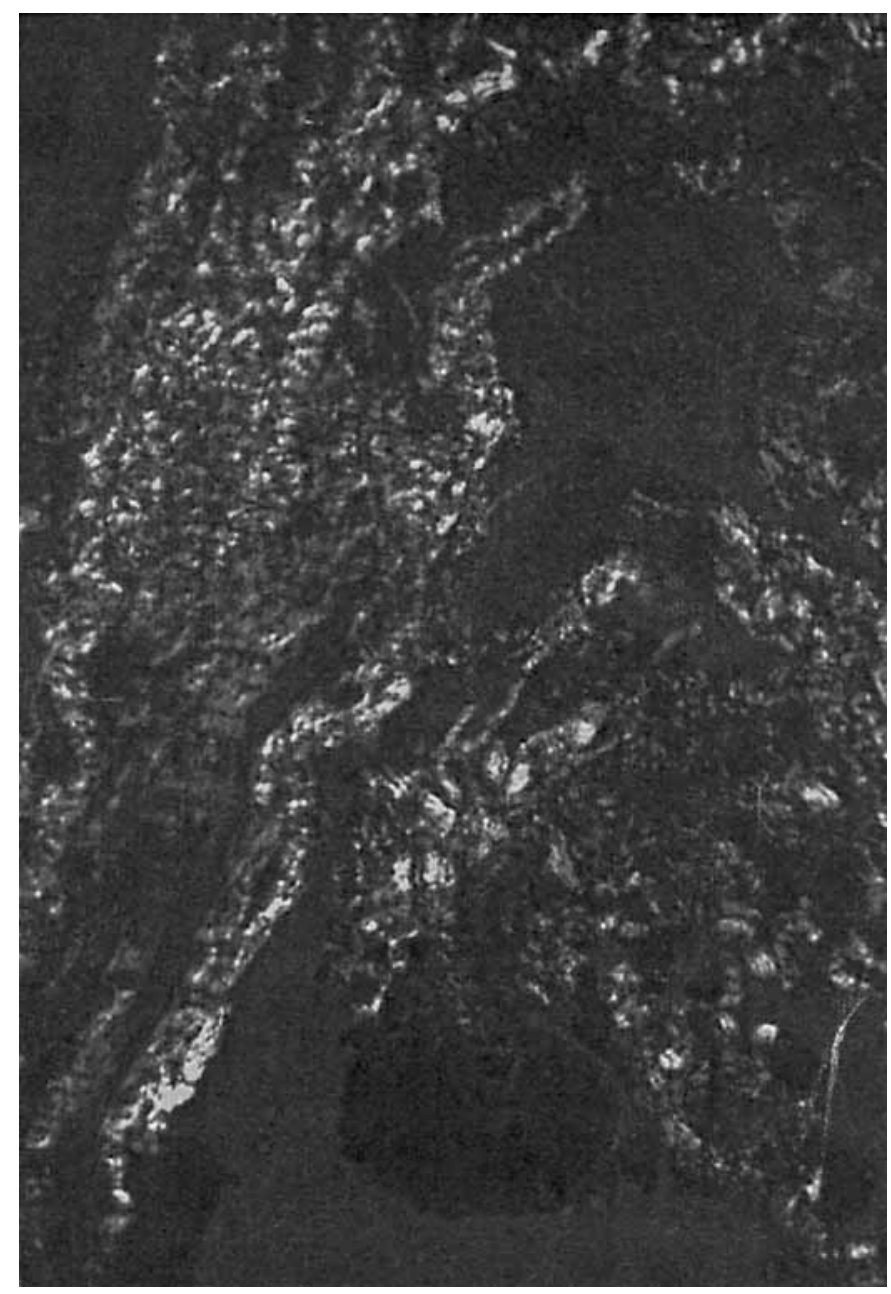

Fig. 4. Microphotograph showing an already moderate interstitial fibrosis (birefringent areas). Sirius-red. $\times 155$.

\section{Discussion}

Pulmonary hemosiderosis is a rare disease, usually seen in children, with an estimated incidence of about 2 out of 100,000 children/year [3, 15]. Most of the affected children die within 2-5 years after clinical diagnosis. It can also occur in young adults, who have a more favorable prognosis, with intermittent silent periods lasting for up to 20 years between two attacks of the disease. The clinical history is not characterized by distinct features. Most frequently, there is a mild onset of cough, lethargy and dyspnea, with increasing tendency for a few months before the patients ask for medical examination. Hemop- tysis is rather rare. In $20-50 \%$ of the patients, blood eosinophilia can be observed, and elevated IgA levels have been reported to occur in about $50 \%$ of the patients [3].

The clinical history of the presented patient was characterized by a sudden onset of dyspnea and moderate hemoptysis occurring a few days after exposure to the above-listed pesticides. The serum levels of the analyzed immunoglobulin classes and enzymes were within the normal range. Autoantibodies or other abnormalities of the immune system could not be detected. The chest radiographs displayed cloudy densities in both lower lobes, which could either be related to the primary source of bleeding or to aspirated blood. The leading symptom was recurrent hemoptysis, which needed multiple blood transfusions every 4-5 days. Therapy with prednisone $(50 \mathrm{mg} /$ day $)$ was not effective, and only the additional application of cyclophosphamide could stop the bleedings and improve the clinical course.

The light-microscopical findings are characteristic for hemosiderosis: preserved lung parenchyma with some interstitial inflammatory infiltrates, agglutinations of hemosiderin-loaded macrophages within the alveoli, hyperplasia and dysplasia of the alveolar lining cells, focal fibrin deposits and a mild to moderate interstitial diffuse fibrosis. The absence of carbohydrate-binding proteins in the pneumocytes is in agreement with the hypothesis of a noninfectious disease [21-23], as corroborated by the immunohistochemical findings of a disturbance of the cellular immune system within the lung assessed by the absence of MIF and MIF-specific binding capacities. Infectious diseases frequently induce the expression of neoglycoprotein-reactive determinants, whereas noninfectious inflammatory diseases such as autoimmune disorders, drug reactions or to some part sarcoidosis are accompanied by the 'normal' status of carbohydrate-binding capacities, i.e. negative ligandohistochemical reactions [3, 21-23]. Immunosuppressive substances appear to improve the course of diseases accompanied by a lack of receptor expression $[3,21]$. The recurrent hemoptysis stopped when cyclophosphamide was applied. This response of an idiopathic pulmonary hemosiderosis to cyclophosphamide has been reported in several cases $[3,11$, $14,23]$.

In contrast to the still unknown etiology of the so-called idiopathic pulmonary hemosiderosis, this young patient inhaled pesticides 3 days prior to the onset of the disease. Jarvis et al. [24] investigated a cluster of cases with pulmonary hemosiderosis in infants and could isolate the toxigenic fungus Memnoniella echinata which produces two cytotoxic trichothecene mycotoxins. In our case, the 
applied pesticide substances can be characterized as synthetic peritroids (deltamethrin, bensultap and cyhalotrin). They have been reported to be irritating for the skin and respiratory system [25]. Deltamethrin can induce paresthesias and tremor, whereas bensultap can lead to increased secretion from the nose, eyes and mouth as well as diarrhea in mammals. These substances have been grouped into the toxicity classes III and IV, respectively, which correspond to a lethal dose LD50 of $50-500 \mathrm{mg} / \mathrm{kg}$ (class III) and 500-2,000 mg/kg (class IV; mg substance/ body weight) in mice according to the Swiss toxicity grading, or according to poisonous (class III) or harmful (class IV) substances in the German or European scheme. Whether their inhalation will have a direct impact on the vascular and immune systems which can lead to the observed severe bleeding, or whether it is only able to aggravate an already established lesion in the respiratory system, remains to be unequivocally established. The close association in time and space between the clearly documented inhalation of the toxic substances and the onset of the bleeding justifies to assume a more than phenomenological correlation between exposure to the exogenous noxae, whose individual impacts can presently not be laid down beyond any doubt, and the clinical manifestation of the so-called idiopathic hemosiderosis. Therefore, a thorough clinical history is mandatory in cases with pulmonary hemosiderosis.

\section{Acknowledgement}

This work was financially supported by the Deutsche Krebshilfe and the Verein zur Förderung des biologisch-technologischen Fortschritts in der Medizin e.V., Heidelberg, Germany.

\section{References}

1 Buschman DL, Ballard R: Progressive massive fibrosis associated with idiopathic pulmonary hemosiderosis. Chest 1993;104:293-295.

2 Goodpasture EW: The significance of certain pulmonary lesions in relation to the etiology of influenza. Am J Med Sci 1919;158:289-297.

3 Kayser K: Analytical Lung Pathology. Berlin, Springer, 1992.

4 Albelda SM, Gefter WB, Epstein DM, Miller WT: Diffuse pulmonary hemorrhage: A review and classification. Radiology 1984;154:289297.

5 Bradley JD: The pulmonary hemorrhage syndromes. Clin Chest Med 1982;3:593-605.

6 Dail DH, Hammar SP, Colby TV: Pulmonary Pathology. Berlin, Springer, 1995.

7 Leaker B, Cambridge G, du Bois RM, Neild $\mathrm{GH}$ : Idiopathic pulmonary hemosiderosis: A form of microscopic polyarteritis? Thorax 1992;47:988-990.

8 Leatherman JW, Davies SF, Hoidal JR: Alveolar hemorrhage syndromes: Diffuse microvascular lung hemorrhage in immune and idiopathic disorders. Medicine 1984;63:343-361.

9 Rezkalla MA, Simmons JL: Idiopathic pulmonary hemosiderosis and alveolar hemorrhage syndrome: Case report and review of the literature. S D J Med 1995;48:79-85.

10 Cataldo F, Varrica D, Violante M, Viani G, Albeggiani A, Ugazio AG: Clinical and pathogenetic observation in a case of pulmonary hemosiderosis. Minerva Pediatr 1995;47:3337 .
11 Thurlbeck WM: Pathology of the Lung. Stuttgart, Thieme, 1988.

12 Blanco A, Solis P, Gomez S, Valbuena C, Telleria JJ: Antineutrophil cytoplasmic antibodies (ANCA) in idiopathic pulmonary hemosiderosis. Pediatr Allergy Immunol 1994;5:235-239.

13 van der Ent CK, Walenkamp MJ, Donckerwolcke RA, van der Laag J, van Diemen-Steenvoorde R: Pulmonary hemosiderosis and immune complex glomerulonephritis. Clin Nephrol 1995;43:339-341.

14 Colombo JL, Stolz SM: Treatment of lifethreatening primary pulmonary hemosiderosis with cyclophosphamide. Chest 1992;102:959960.

15 Fossati G, Perri M, Careddu G, Mirra N, Carnelli V: Pulmonary hemosiderosis induced by cow's milk proteins: A discussion of a clinical case. Pediatr Med Chir 1992;14:203-207.

16 Perelman S, Dupuy C, Bourrillon A: The association of pulmonary hemosiderosis and celiac disease. Apropos of a new case in a child. Ann Pediatr 1992;39:185-188.

17 Wright P, Menzies I, Pounder R, Keeling P: Adult idiopathic hemosiderosis and celiac disease. Q J Med 1981;197:95

18 Yacoub M, Mahjoub H, Abroug S, Bousnina M, Harbi A, Essoussi AS: Idiopathic pulmonary hemosiderosis, celiac disease and cardiomyopathy. Arch Pediatr 1994;1:587-590.
19 Pinto M, Correia J, Leal I, Reis A, LeAao B, de Carvalho S, Sousa CS: Idiopathic pulmonary hemosiderosis. Acta Med Port 1996;9:41-44.

20 Ahmad D, Morgan WKC, Patterson R, Williams T, Raymond Zeiss C: Pulmonary hemorrhage and hemolytic anemia due to trimellitic anhydride. Lancet 1979;ii:328-330.

21 Kayser K, Bohrer M, Kayser C, Weiser WY, Zeng F-Y, Gabius H-J, Tüngerthal S, Schulz V: Alteration of human lung parenchyma associated with primary biliary cirrhosis. Zentralbl Pathol 1993;139:377-380.

22 Kayser K, Gabius H-J, Carls S, Bubenzer J: Alterations of human lung parenchyma after cytostatic therapy. APMIS 1991;99:121-128.

23 Kayser K, Paul K, Feist D, Hofmann W, Wille L, Gabius H-J: Alteration of the lung parenchyma associated with autoimmune hepatitis. Virchows Arch A Pathol Anat Histopathol 1991; 419:153-157.

24 Jarvis BB, Zhou Y, Jiang J, Wang S, Sorenson WG, Hintikka EL, Nikulin M, Parikka P, Etzel RA, Dearborn DG: Toxigenic molds in waterdamaged buildings: Dechlorogriseofulvins from Memnoniella echinata. J Nat Prod 1996; 59:553-554.

25 Dreisbach RH: Handbook of Poisoning: Prevention, Diagnosis and Treatment. Washington, Prentice-Hall International, 1987. 